\title{
SENTIMENTOS DOS PROFISSIONAIS DE ENFERMAGEM MEDIANTE A PANDEMIA CAUSADA PELO NOVO CORONAVÍRUS
}

\section{Fernanda Vieira Lobato ${ }^{1}$; Ana Caroline Freitas de Almeida ${ }^{2}$; Leticia Lopes da Silva Santos ${ }^{3}$; Giane Elis de Carvalho Sanino ${ }^{4}$}

\author{
${ }^{1}$ Graduanda em Enfermagem, Universidade Paulista (UNIP), São Paulo, São Paulo. \\ ${ }^{2}$ Graduanda em Enfermagem, Universidade Paulista (UNIP), São Paulo, São Paulo. \\ ${ }^{3}$ Graduanda em Enfermagem, Universidade Paulista (UNIP), São Paulo, São Paulo. \\ ${ }^{4}$ Doutora em Educação, Universidade Paulista (UNIP), São Paulo, São Paulo.
}

DOI: 10.47094/IICNNESP.2021/132

\begin{abstract}
RESUMO
Introdução: O mundo vivencia uma pandemia causada pelo novo Covid - 19, o qual submeteu os profissionais a novas cargas e jornadas de trabalhos exaustivas. Como consequência dessa realidade, a equipe de enfermagem encontra - se em parte de uns dos grupos afetados e expostos ao risco de contágio. Metodologia: foi efetuado um estudo de revisão sistemática da literatura no período de 2 meses. Fundamentação teórica: sentimentos como preocupações com contaminação, exaustão física, sobrecarga, ansiedade, depressão, raiva e irritabilidade, desamparo e angústia, estão predominantes nos profissionais de enfermagem pois se encontra exposta a riscos, desvalorização social e salarial, carga horária excessiva, ausência de materiais e ambientes insalubres. Considerações finais: concluiuse que os sentimentos dos profissionais de enfermagem mediante a pandemia do novo coronavírus precisam de atenção imediata levando em consideração que a equipe de enfermagem atua na linha de frente.
\end{abstract}

PALAVRAS-CHAVE: Sars Cov2. Saúde. Sensações.

ÁREA TEMÁTICA: Saúde Física e Mental

\section{INTRODUÇÃO}

A pandemia do novo coronavírus (COVID-19) chamou a atenção pela rapidez que se disseminou e pela sua repercussão em nível mundial. Pelo constante aumento do número de infectados e da exigência de cuidados para os casos mais graves, os profissionais de saúde foram considerados grupo de alto risco para contaminação. Por atuarem na linha de frente, estão em maior vulnerabilidade para o adoecimento.

Enfermeiros, Técnicos e Auxiliares de Enfermagem estão entre os trabalhadores da saúde que são a maioria nos serviços públicos e privados, sendo considerados essenciais e nucleares na estrutura. Os profissionais de Enfermagem se veem responsáveis pelo bem-estar dos pacientes, 
assumindo o compromisso em meio a um contexto totalmente novo. Devido a aparição inesperada do COVID-19 e a importância da enfermagem frente a este momento, o presente estudo visa evidenciar como estão os sentimentos dos profissionais de enfermagem durante a pandemia com o intuito de contribuir para a criação de estratégias de prevenção que possam ajudá-los no cenário atual com o objetivo de identificar na literatura os sentimentos dos profissionais de enfermagem em relação à pandemia causada pelo Sars Cov2.

\section{METODOLOGIA}

Foi elaborado um estudo de revisão sistemática da literatura, no período de 2 meses, para responder a seguinte pergunta de pesquisa: Quais são os sentimentos dos profissionais de enfermagem mediante a pandemia do novo coronavírus? A busca foi realizada na base de dados da Biblioteca Virtual em Saúde (BVS) utilizando os seguintes descritores: sentimentos and enfermagem and coronavírus. Os critérios de inclusão e exclusão foram: artigos publicados entre os anos de 2016 e 2021, disponíveis gratuitamente. Artigos de revisão e duplicados foram excluídos, bem como os que estavam fora do recorte temporal estabelecido. Após a leitura do texto integralmente, foram encontrados 23 artigos, os quais poderiam se repetir por estarem presentes em mais de uma base de dados. Para a elaboração geral do trabalho foram selecionados 7 artigos, por estes artigos estarem de acordo com o objetivo proposto pelo trabalho, assim, após a inclusão do artigo, esse foi separado por categorias temáticas: preocupação com contaminação; exaustão física; ansiedade; raiva e irritabilidade; depressão; gratidão e esperança; desamparo e angústia. Os resultados foram analisados buscando esclarecer o objetivo e verificar a presença de lacunas na literatura.

\begin{tabular}{|c|c|c|c|}
\hline & Sentimentos & $\mathrm{n}$ & $(\%)$ \\
\hline & $\begin{array}{l}\text { Preocupação com Contaminação (contaminação de } \\
\text { familiares, contaminar-5e, disseminação do virus) }\end{array}$ & 7 & 100 \\
\hline & $\begin{array}{l}\text { Exaustão fisica (fadiga, sobrecarga, deterioração fisica, } \\
\text { desconforto) }\end{array}$ & 5 & 71,4 \\
\hline & Ansiedade & 4 & 57,1 \\
\hline & Raiva e irritabilidade & 4 & 57,1 \\
\hline & Depressão & 4 & 57,1 \\
\hline & Gratidão e Esperança & 3 & 42,8 \\
\hline & Desamparo e Angúatia & 3 & 42,8 \\
\hline
\end{tabular}

\section{FUNDAMENTAÇÃO TEÓRICA}

Com base nos sentimentos mais recorrentes pode-se levantar categorias temáticas e observar como cada um desses sentimentos afetam o cotidiano da equipe de enfermagem.

Nesse período onde a pandemia está em um crescimento exponencial, os profissionais de enfermagem lidam com a preocupação com seus familiares. O medo excessivo de contrair a doença e levar para seus entes queridos aumentam nesses dias. Estar próximo da família e ser acolhido é 
um dos fatores motivadores nesse momento de pandemia, no entanto com as mudanças na rotina e a preocupação de transmissão do vírus causa um grande tristeza e frustração, pois necessitam está longe dos seus familiares.

Há ansiedade para manterem o cuidado com a prevenção individual e coletiva, esse comportamento, se tornam mecanismos de riscos para a infecção, pela interferência da autocobrança.

Os profissionais de enfermagem apresentam uma predisposição maior para o sofrimento mental sendo que a depressão é a terceira causa de doenças mentais nesses profissionais, isso não ocorre somente pelas atividades realizadas por eles, e sim está relacionada ao sofrimento físicos, emocionais, condições de trabalhos e falta de reconhecimento profissional.

A tensão atender pacientes se intensifica no cenário da pandemia do novo corona vírus com transmissão e sem tratamento específico, além disso, suas vidas estão em risco constantemente, ocasionando uma situação realmente perigosa para si mesmo e para seus familiares, os outros fatores estressores podem ser elucidados, como pacientes em estado grave; número limitado de ventiladores mecânicos e leitos de UTI, esses fatores podem diretamente implicar no desencadeamento de depressão e crises de ansiedade.

A pandemia do coronavírus gerou grande preocupação com a saúde mental da equipe de enfermagem diante ao enfrentamento do covid-19, pois as jornadas de trabalhos excessivas, podem ocasionar perturbações psicológicas e mentais e interferir na qualidade de vida dos profissionais, levando a Síndrome de Burnout.

Uma entrevista realizada com um grupo médico de um hospital chines, alguns profissionais demonstraram sinais de irritabilidade, angústia excitabilidade. Além disso, relataram que a falta de colaboração dos pacientes estava causando maiores sofrimentos psicológicos, porque muitos não respeitavam as medidas preventivas de disseminação do vírus, consequentemente aumentando as chances de sobrecarregarem as unidades hospitalares.

A exaustão física, dentro deste estudo, engobla todas as percepções fisicas levantadas pelos artigos analisados, como: fadiga, deterioração física e desconforto físico. Determinado isto, pode-se observar que a existência de desgate físico na equipe de enfermagem por conta do grande volume de trabalho no tratamento de pacientes que contrairam o coronavírus, e o desconforto físico causado pela utilização dos EPIs pelo fato de incomodarem, machucarem e limitarem os movimentos, apesar de ser de suma importância para a proteção.

Além de que depois de paramentados os profissionais ficam impossibilitados de comer ou ir ao banheiro por cerca de seis horas, só realizando essas necessidades básicas após a desparamentação correta.

E apesar de todos sentimentos negativos, uma grande porcentagem dos artigos apresentou o sentimento de gratidão, orgulho e esperança dentro da equipe de enfermagem. Há a sensação de dever cumprido à cada alta de paciente, e esperança de que a disseminação do vírus seja contida, que diminua o número de pessoas infectadas e mortas e que toda a população seja imunizada. 


\section{CONSIDERAÇÕES FINAIS}

Baseado nos estudos retratados pode-se observar diversos sentimentos que o aparecimento do Covid-19 trouxe para a vida dos trabalhadores de enfermagem, foram identificadas sete principais categorias temáticas para o desenvolvimento desta pesquisa, dentre deles: preocupação com contaminação; exaustão física; ansiedade raiva e irritabilidade; depressão; desamparo e angústia; Gratidão e esperança.

Com o aumento da carga horária de trabalho, com as notícias cada vez mais alarmantes relacionadas ao número de mortos e infectados, com a falta muitas vezes de equipamentos de proteção individual, entre outros, percebe-se que estas situações citadas e principalmente o medo da contaminação têm prejudicado a saúde mental da equipe de enfermagem.

Desta forma, concluiu-se que os sentimentos dos profissionais de enfermagem mediante a pandemia do novo coronavírus são alarmantes e precisam de atenção imediata levando em consideração que a equipe de enfermagem atua na linha de frente e são os profissionais que mais possuem contato direto com o paciente. Cuidar de quem cuida é importante para evitar desgaste físico e emocional e desta forma evitar que eventos adversos aconteçam durante a prática de trabalho.

\section{PRINCIPAIS REFERÊNCIAS}

DE HUMEREZ, Dorisdaia Carvalho; OHL, Rosali Isabel Barduchi; DA SILVA, Manoel Carlos Neri. Saúde mental dos profissionais de enfermagem do brasil no contexto da pandemia covid-19: ação do conselho federal de enfermagem. Cogitare Enfermagem, v. 25, 2020.

OLIVEIRA, Eliany Nazaré et al. Projeto Vida em Quarentena: estratégia para promoção da saúde mental de enfermeiros diante da COVID-19. Enferm. foco (Brasília), p. 162-167, 2020.

GALVÃO, Drielly da Silva et al. Aspectos psicossociais de acadêmicos de Enfermagem durante a pandemia da COVID-19. Enferm. foco (Brasília), p. 143-147, 2020. 